\title{
Organic free radicals as circularly polarized luminescence emitters
}

\author{
Paula Mayorga Burrezo, ${ }^{[a]}$ Vicente G. Jiménez, ${ }^{[b]}$ Davide Blasi, ${ }^{[a]}$ Imma Ratera, ${ }^{[a]}$ Araceli G. \\ Campaña, ${ }^{*[b]}$ and Jaume Veciana*[a]
}

\begin{abstract}
Chiroptical properties of two chiral atropisomers of propeller-like trityl-based radical derivatives have been analyzed. A new absolute configuration (AC) assignment has been made, according to the combination of experimental and theoretical data. In this sense, their ACs have been determined through the comparison of the Cotton effects recorded by electronic circular dichroism (ECD) with the theoretical ECD of the open shell structures obtained by TDDFT calculations. Finally, their circularly polarized luminescence $(\mathrm{CPL})$ responses have been addressed. Remarkably, this is the first description of organic free radicals as intrinsic CPL emitters. Opposite signed CPL has been detected for each pair of conformers, with acceptable luminescent dissymmetry factors $\left(\left|\mathrm{g}_{\mathrm{lum}}\right| \approx 0.5-0.8 \times 10^{-3}\right)$ considering their pure organic nature. In fact, highly efficient chiral emissions have been demonstrated, according to the comparison of $\left|g_{\text {lum }}\right|$ with their respective absorption anisotropy factors $\left(\left|g_{a b s}\right|\right)$. This pioneering study lays the foundations for the optimizations of new magnetically active organic chiral emitters.
\end{abstract}

\section{Introduction}

The development of luminescent materials based on supramolecular or polymeric structures has been a recurrent topic for organic chemists along the years. However, light emission from organic small molecules, has not been so exploited, and even less in the case of circularly polarized light. ${ }^{[1]}$ When considering chiral, non-racemic luminescent systems, the emission of light is spontaneously differentiated between left $\left(I_{L}\right)$ and right $\left(I_{R}\right)$ circularly polarized radiation. Thanks to this phenomenon, basis of the circularly polarized luminescence $(\mathrm{CPL})$ spectroscopy, ${ }^{[2]}$ valuable knowledge about the chirality of the excited states can be extracted. For this reason, CPL is usually considered as a complementary technique to electronic circular dichroism (ECD) spectroscopy, which is devoted to the ground states. Besides their obvious applications into lightemitting devices, ${ }^{[3]-[5]}$ several are the additional functionalities that can be assigned to $\mathrm{CPL}$ responsive structures, including molecular switches ${ }^{[6]-[9]}$ and ratiometric probes, ${ }^{[10]}$ etc. Therefore, the development of new materials behaving as chiral

[a] Dr. P. Mayorga Burrezo, Dr. D. Blasi, Dr. I. Ratera, Prof. J. Veciana Department of Molecular Nanoscience and Organic Materials Institut de Ciència de Materials de Barcelona (ICMAB)/ CIBER-BBN Campus Universitari de Bellaterra. E-08193, Cerdanyola, Barcelona, Spain.

E-mail: vecianaj@icmab.es

[b] V. G. Jiménez, Dr. A. G. Campaña Department of Organic Chemistry, University of Granada (UGR)

C. U. Fuentenueva, 18071 Granada, Spain.

E-mail: araceligc@ugr.es

Supporting information for this article is given via a link at the end of the document. chromophores with intrinsic CPL response is an appealing topic within the chiroptic research area.

Exclusively considering the case of chiral small molecules, metalorganic structures based on $d$ - or f-metals, such as lanthanide complexes, are nowadays leading the race on the achievement of high efficient emitters, regarding the values of their luminescent dissymmetry factors $\left(\left|g_{\text {lum }}\right|=2\left(I_{L}-I_{R}\right) /\left(I_{L}+I_{R}\right)\right)$ reported so far. ${ }^{[11]}$ On the contrary, great efforts are being invested for purely organic systems to reach this front position and new sophisticated structures are being developed with $\left|g_{\mid u m}\right| \leq 10$ ${ }^{1} \cdot{ }^{[12]-[14]}$ In fact, they are considered as more promising CPL emitters thanks to their easily tuned emission wavelength and efficiency through rational structural modifications. In this sense, systems based on helical, ${ }^{[15]-[18]}$ or axia|l ${ }^{[19],[20]}$ chirality have been studied. Nonetheless, propeller chirality with CPL response has been poorly analyzed yet. ${ }^{[21],[22]}$

Triphenylmethyl (trityl) radical-based chlorinated derivatives ${ }^{[23]}$ are the simplest examples of stable carbon-centered molecular propellers. ${ }^{[24]}$ They exist in racemic mixtures of Minus $(M)$ and Plus $(P)$ enantiomers, ${ }^{[25]}$ depending on the left- or right-handed torsion of the three rings protecting the odd electron, mainly located in the central $\mathrm{sp}^{2} \alpha$-carbon. Besides their electronic and magnetic properties, ${ }^{[25]}$ the open-shell character also confers interesting optical and optoelectronic properties to these structures. For instance: (i) the common fluorescence quenching related to non-doublet excited states is avoided by their unusual emission via the doublet excited state; (ii) despite the absence of elongated $\pi$-systems, longer emission wavelengths can be accounted for; and (iii) large emission lifetimes (on the order of tens of ns), among others. Tris(2,4,6-trichlorophenyl)methyl[26] and perchlorotriphenylmethy| ${ }^{[27]}$ radicals (1 and 2 respectively in Figure 1) are two common persistent trityl derivatives which show photoluminescence. ${ }^{[28],[29]}$ In spite of some drawbacks concerning their photostability in solution, the preparation of organic light emitting diodes (OLEDs) with electroluminescent layers based on 1 $^{[30],[31]}$ have been successfully achieved and, very recently, the highest value of external quantum efficiency for a deep-red and infrared OLED have been reported. ${ }^{[32]}$ Several synthetic approaches have been pursued aiming to obtain higher photostability and luminescence quantum yield (LQY) or redshifted emissions ${ }^{[33]-[39]}$ for this organic radical, highlighting its great tailorability. Finally, the influence of rigid environments on their luminescent properties have also been considered. Not only improved values of LQY were found but also excimers formation in different host matrices, was proved. ${ }^{[40]}$ As a consequence, modulation between monomer- and excimer-centered emission bands in organic radicals by the application of a magnetic field has been recently observed. ${ }^{[41]}$

Remarkably, nothing has been said yet about the influence of the intrinsic chirality of these materials on their emissive properties, although some hints about the stability of their isolated enantiomers can be found in the literature. ${ }^{[42]-[44]}$ 
<smiles>Clc1ccc(C(Cl)C(c2cc(Cl)ccc2Cl)(c2c(Cl)cccc2Cl)c2c(Cl)cc(Cl)cc2Cl)c(Cl)c1</smiles>

$(P)-1$

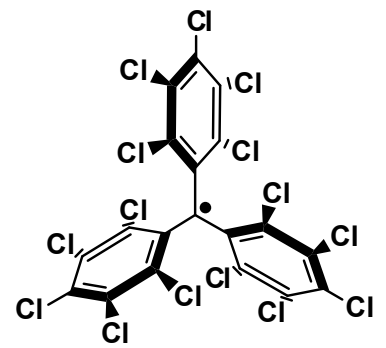

$(P)-2$

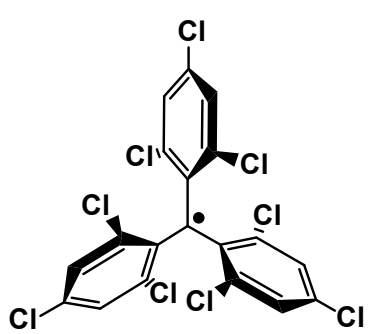

(M)-1

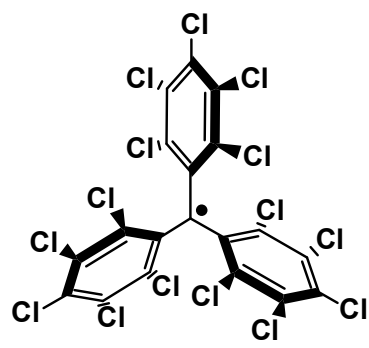

$(M)-2$

Figure 1. Chemical structures of 1 and 2. Enantiomers, Plus $(P)$ and Minus $(M)$, of the two trityl-based radicals.

In fact, to the best of our knowledge, the combination of chirality, luminescence and magnetism in a single organic molecule has never been addressed, despite all the advantage that the openshell character may provide. Bearing all these ideas in mind, herein we present, for the first time, a study about the intrinsic CPL response in organic free radicals, considering trityl-based radical chlorinated-derivatives for such a purpose. In particular, two structures with different grade of halogenated substitution have been chosen (see $\mathbf{1}$ and $\mathbf{2}$ in Figure 1). In this sense, we will first revisit the stereochemistry of these compounds, getting further insights into the influence of the chlorinated shields on their racemization kinetics. Then, taking into account all the progress already made about the photophysics of these particular radicals, the best conditions for addressing the CPL measurements will be considered. We strongly believe that the results achieved with this work may represent an important milestone for the development of new chiral organic emitters.

\section{Results and Discussion}

The resolution of the racemic compounds $\mathbf{1}$ and $\mathbf{2}$ into their two possible enantiomers was faced by chiral stationary phase (CSP)HPLC, taking full advantages of the different degrees of molecular association that each enantiomer of a racemic sample can have with a chiral environment. A preliminary (CSP)HPLC optimization study allowed the identification of the best chromatographic conditions for the enantioresolution of both samples. A cellulose-based stationary phase and a 99.9:0.1 (v/v) hexane/dichloromethane mixture as eluent, under isocratic

conditions, at room temperature were used for such purpose. Figure 2 depicts the obtained (CSP)HPLC chromatograms, with an UV-Vis absorption detection set at the wavelength of maximum absorbance in these experimental conditions. This is: $370 \mathrm{~nm}$ and $385 \mathrm{~nm}$ for compound $\mathbf{1}$ and 2, respectively. Satisfactory separations were achieved in order to further collect enantioenriched solutions of each pair of enantiomers. The same method was used in both cases, due to the high similarity of both structures. However, it resulted in larger differences in the retention times of $2\left(t_{R}(1)=5.54 / 6.40 \mathrm{~min}\right.$ and $t_{R}(2)=8.73 /$ $13.88 \mathrm{~min}$ ) and, consequently, a considerably better resolution $(\mathrm{Rs})$ for this radical $(\mathrm{Rs}(1) \approx 1$ and $\mathrm{Rs}(2)=2.11$. See Section 1 of SI for further details). Additionally, in the case of 1 , due to the overlapping areas of the two (CSP)HPLC fractions, the corresponding enantioenriched compounds were isolated in an enantiomeric excess (e.e.) of $43 \%$ in $(M)-1$ and $66 \%$ in $(P)-1$ (Section 2 of SI file).

Aiming to go into detail, the first order constant rates of enantiomerization, $\mathrm{k}_{1}$ and $\mathrm{k}_{-1}$, were determined by using the analytical function of the unified equation, ${ }^{[45]}$ simulating the (CSP)HPLC elution profiles, and the following values were obtained $\left(\mathrm{x} \mathrm{10}^{-4}\right.$, in $\left.\mathrm{s}^{-1}\right)$ : $9.63 / 6.93$ for 1 and $2.55 / 2.40$ for 2 (Section 3 of SI). The substitution of the ortho- positions of the phenyl rings in these compounds plays a key role in order to achieve highly inert structures. Nonetheless, according to these data, it is safe to say that conferring a fully chlorinated shield causes a greater conformational stability. This can be ascribed to the buttressing effect imparted by the meta- chlorine atoms. ${ }^{[46]}$
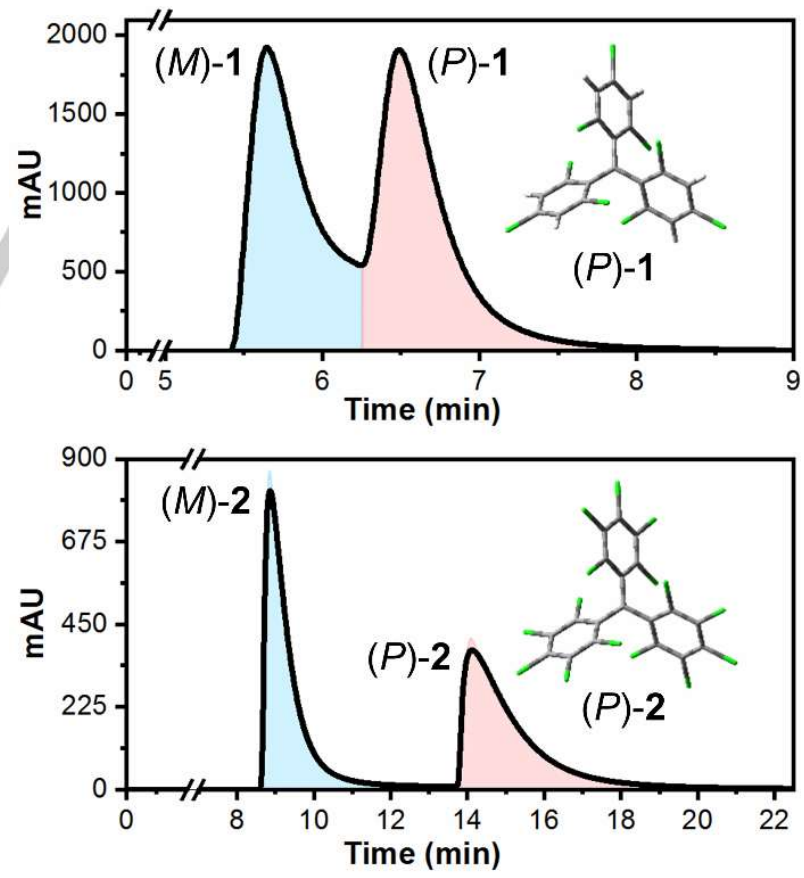

Figure 2. CSP)HPLC chromatograms for compound 1 and 2, respectively with $(M)$-(blue) and $(P)$-(red) enantiomers. Additionally, the corresponding DFTublyp/6-311+g(d,p)-optimized structures for $(P)$ - enantiomers are shown. The stereochemical assignments were determined by comparison of experimental and calculated ECD spectra (see Figure 3). 

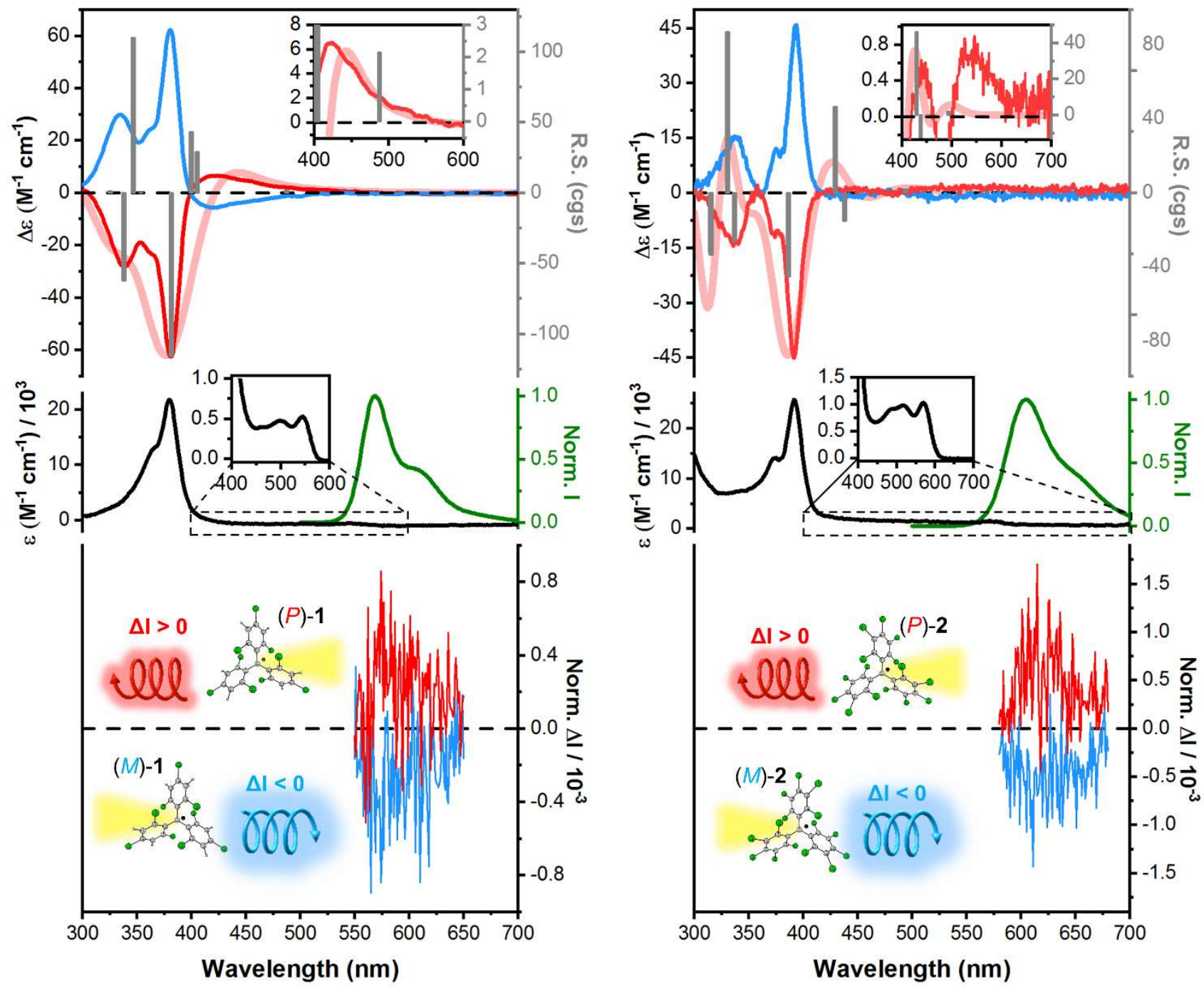

Figure 3. Top: Experimental ECD spectra (in CCl4, at $-20^{\circ} \mathrm{C}$ ) of the first (blue) and second (red) (CSP)HPLC fractions of 1 (10-4 $\mathrm{M}$, left) and $2\left(10^{-5} \mathrm{M}\right.$, right) together with the calculated ECD spectra of $(P)$-enantiomers (thick light red line). The sticks (dark grey) indicate the positions and rotatory strengths of the calculated transitions. In the case of 1, the experimental ECD spectra were corrected in terms of an enantiomeric excess factor (see ¡Error! No se encuentra el origen de la referencia.). Insets: Experimental $\left(\sim 10^{-4} \mathrm{M}\right.$, in CCl4, at $\left.-20^{\circ} \mathrm{C}\right)$ and theoretical ECD D bands from $(P)$-enantiomers. Central: Experimental UV-Vis absorption spectra (in $\mathrm{CCl} 4$, at $-20^{\circ} \mathrm{C}$, in black) of $1\left(\sim 10^{-4} \mathrm{M}\right.$, left $)$ and $2\left(\sim 10^{-5} \mathrm{M}\right.$, right), together with the total fluorescence spectra $\left(\sim 10^{-5} \mathrm{M}\right.$ in $\mathrm{CCl} 4$, at $-20^{\circ} \mathrm{C}$, in green). Insets: Experimental $\left(\sim 10^{-4} \mathrm{M}\right.$, in $\mathrm{CCl} 4$, at $\left.-20^{\circ} \mathrm{C}\right)$ UV-Vis absorption D bands (See Fig. S11 of SI for theoretical UV-Vis absorption spectra). Bottom: CPL spectra of the first (blue) and second (red) (CSP)HPLC fractions of 1 (left) and $\mathbf{2}$ (right) $\left(10^{-4} \mathrm{M}\right.$, in $\mathrm{CCl} 4$, at $-20^{\circ} \mathrm{C}$ ), with $\lambda_{\text {exc }}$ set to UV-Vis $\mathrm{C}$ bands. Additionally, a schematic representation of the CPL response of the two enantiomers of 1 (left) and $\mathbf{2}$ (right) has been included, with $\Delta \mathrm{I}>0$ for $(P)$-enantiomers and $\Delta \mathrm{I}<0$ for $(M)$ - enantiomers

However, it is known that, since the calculation of the rate constants from dynamic (CSP)HPLC follows indirect methodologies, some inaccuracy issues may be found in the thermodynamic parameters so obtained. ${ }^{[47]}$ On the contrary, the ECD signal is proportional to the enantiomeric purity, so its exponential decay directly provides the desired rate constant. Consequently, the evaluation of the configurational stability of the residual enantiomers of both samples were properly addressed by means of dynamic ECD ( $d E C D$ ) spectroscopy. In this sense, the evolution with time of one of the (CSP)HPLC fractions was followed at temperatures ranging from 10 to $30^{\circ} \mathrm{C}$ (see Section 4 of $\mathrm{SI}$ ). Supporting the preliminary results obtained from (CSP)HPLC, a slightly superior racemization barrier was found for
2. $\left(\Delta \mathrm{G}^{\ddagger}{ }_{303 \mathrm{~K}}(\mathbf{1})=21.12 \pm 1.77 \mathrm{Kcal} \mathrm{mol}^{-1}\right.$ and $\left(\Delta \mathrm{G}^{\ddagger}{ }_{303 \mathrm{~K}}(\mathbf{2})=22.36\right.$ $\left.\pm 1.92 \mathrm{Kcal} \mathrm{mol}^{-1}\right)$. These values are in good agreement with the ones obtained for 2 by means of polarimetric ${ }^{[44]}$ or HPLC. ${ }^{[42]}$ However, the slight differences found in the actual numbers were attributed to the chosen methodologies. Accordingly to these data, a two-ring flip might be the enantiomerization mechanism in both cases, ${ }^{[48],[49]}$ despite the higher steric hindrance in $\mathbf{2}$. This means that, considering the plane formed by the three aromatic carbons linked to the central radical one, two phenyl rings turn in the same direction, perpendicularly to this plane, while a disrotatory fashion is associated to the third one. 
ECD response was also monitored for the two collected enantiomeric (CSP)HPLC fractions, aiming to assign their absolute configurations (i.e. $\mathrm{AC}$ ), of $(P)$ - or $(M)$-enantiomers. Figure 3 presents the obtained ECD spectra (top) for both enantiomers of $\mathbf{1}$ (left) and $\mathbf{2}$ (right), as well as the corresponding UV-Vis electronic absorption (central). All the experimental spectra were obtained in carbon tetrachloride $\left(\mathrm{CCl}_{4}\right)$ solutions at $-20{ }^{\circ} \mathrm{C}$ (see the calculations of the molar absorptivity for both radicals in Section 5 of $\mathrm{SI}$ ), in order to be consistent with further measurement conditions for $\mathrm{CPL}$ activity and ensure configurational stability. An excellent signal-to-noise ratio and limited baseline drift, even at shorter wavelengths, was achieved. As expected, a perfect match was found between the UV-Vis spectra of the enantioenriched solutions and the racemic mixtures of the radicals. Following the band classification made by Ballester et al., ${ }^{[27]}$ the main UV-Vis features appeared at: $365 / 373$ $\mathrm{nm}$ (B band), 380/392 nm (C band) and [460, 500, 545]/ [488,518, $570] \mathrm{nm}$ ( $D$ band), for $\mathbf{1 / 2}$, respectively. $B$ Band was linked to the $\pi-\pi^{*}$ transition of the aromatic system while $C$ and $D$ bands were ascribed to the trityl radical and, particularly, to the delocalization of the lone-electron through the aromatic rings.

ECD spectra showed a good alignment to the UV-Vis absorption ones measured by conventional spectroscopy. Considering the propeller-shape configuration as the origin of the chiral activity, no great differences with respect to the UV-Vis absorption spectra were expected, due to the presence of additional elements of chirality. In this sense, ECD results showed perfect mirror-image Cotton effects with two main bands (B/C) detected at $335 / 380 \mathrm{~nm}$ for 1 and $339 / 392 \mathrm{~nm}$ for 2 . The absorption anisotropy factor, $\left|g_{\text {abs }}\right|$ $=\Delta \varepsilon / \varepsilon,{ }^{[50]}$ of both radicals was also evaluated and the following values $\left(\times 10^{-3}\right)$ were calculated: $2.99($ at $335 \mathrm{~nm}) / 1.84$ (at $339 \mathrm{~nm}$ ) (B band), 1.38 (at $380 \mathrm{~nm}) / 1.44$ (at $392 \mathrm{~nm}$ ) (C band) and $\approx 0.55$ (at $545 \mathrm{~nm}$ )/ 0.95 (at $552 \mathrm{~nm}$ ) (D band) for 1/2, respectively. ECD response of 2 was previously reported by Irurre et al. ${ }^{[44]}$ and, surprisingly, $B$ band (instead of $C$ band) was the main feature of their ECD spectrum. In that occasion, the AC of both enantiomers was assigned attending to the sign of the Cotton effect of the given band, this is: $(P)-(+)-2$ and $(M)-(-)-2$, following the helicity rules in ECD. ${ }^{[51]}$ In our case, since no monocrystals for X-ray diffraction could be obtained for the optically pure materials, TDDFT methodology was used to assign the experimental data. ${ }^{[52]}$ Particularly, $(P)$-enantiomers were chosen for such purpose and UB3LYP hybrid density functional ${ }^{[53]}$ and a $6-311+G^{* *}$ basis were used, in consonance with previous calculations for ECD spectra of molecular propeller with open-shell configuration ${ }^{[48]}$ (See Section 6 of SI). Singly (un)occupied molecular orbitals (SUMO/SOMO) with fully delocalized electronic densities onto the aromatic rings were obtained (1: $137 \alpha / 137 \beta$ and $2: 185 \alpha / 185 \beta$, Fig. S8-9), in line with what Nishihara et al. ${ }^{[33]}$ and Cornil et al. ${ }^{[54]}$ published for 1 and 2, respectively, with different basis sets. A reasonably good agreement was found between the experimental and theoretical data in both cases (Fig S11). In particular, concordant features were observed between the ECD spectra of the second (CSP)HPLC fractions and the simulated ones for $(P)$ 1 and $(P)$-2. Consequently, and contrary to the cited literature, the first (CSP)HPLC fractions, showing a main positive Cotton effect, were unambiguously verified as $(M)-1$ or 2 and the second (CSP)HPLC fractions, with a main negative Cotton effect, as $(P)$ 1 or 2. Notwithstanding, lower-energy ECD electronic transition, related to the $D$ bands, were also observed in the experimental spectra at 542 and $\approx 550 \mathrm{~nm}$, for 1 and 2 respectively, and supported by TD-DFT methodology (see the insets in Figure 3, top). Remarkably, opposite Cotton effect were found to that of the main C bands, for instance: (-) 380/ (+) $500 \mathrm{~nm}$ for 1 and (-) 392/ (+) $552 \mathrm{~nm}$ for 2 , considering the second (CSP)HPLC fractions. It has been probed in the case of carbo[n]helicenes ${ }^{[55]}$ that the sign of minor absorption bands at longest wavelengths can play a relevant role, since they usually determine the sign of the CPL spectrum. ${ }^{[56]}$ According to this point, further CPL measurements would also shed light on this matter, from the analogy between propeller and helical chirality.

Lastly, CPL response of these trityl-based radicals was explored for the first time. Specific experimental conditions were used, considering the limitations imposed by the given samples with respect to the technique requirements. On one hand, good CPL signals are only reached when large $\left|g_{\text {lum }}\right|$ and LQY values are achieved. ${ }^{[1]}$ On the other hand, it has been demonstrated by some of us that a drastically enhancement of the LQY occurs when these structures are confined in a rigid host. ${ }^{[40]}$ Unfortunately, solid media, as frozen glasses, are considered as birefringent elements since they can produce optical artifacts. ${ }^{[57]}$ In fact, CPL in glassy 2-methyl THF at $77 \mathrm{~K}$ was checked and a significant contribution of linear polarization was found. Thus, the luminescence of $(P)-1$ and $(P)-2$ was investigated in viscous $\mathrm{CCl}_{4}$, in line with some previous studies, ${ }^{[28],[29]}$ where no excimeric bands ${ }^{[40]}$ were found due to the good solvation of the isolated radicals. With the aim of reaching the highest possible LQY, the excitation wavelengths $\left(\lambda_{\text {exc }}\right)$ were fixed at their respective UV-Vis $C$ bands wavelengths ${ }^{[29]}$ since no dependency on the $\lambda_{\text {exc }}$ was proved for the emission spectra of these radicals. ${ }^{36}$ A perfect match was found between the enantioenriched and racemate solutions (maximum emission wavelength, $\lambda_{\mathrm{em}}=569 \mathrm{~nm}$ and 605 $\mathrm{nm}$ for $\mathbf{1}$ and 2, respectively, Figure $\mathbf{3}$ (central) and Fig. S14) as occurred with the ECD response. Additionally, the effectiveness of the emission was pointed out by the small Stokes shifts values (774 and $1015 \mathrm{~cm}^{-1}$ for 1 and 2, respectively, Table S8), considering the UV-Vis D bands. Two crucial aspects were taken into account when facing the CPL measurements. Firstly, the temperature was set to $-20{ }^{\circ} \mathrm{C}\left(\mathrm{mp} \mathrm{cCl}=-23{ }^{\circ} \mathrm{C}\right)$, aiming at minimizing the racemization processes (Fig. S15). On top of that, the desirable homogenous viscous media for increasing the LQY was guaranteed without the effect of additional polarizations that cover up the actual CPL. ${ }^{[58]}$ Thus, no high LQY were achieved at this temperature: 0.072 for 1 (i.e., 0.72 at $77 \mathrm{~K}$ in 2-methyl THF) ${ }^{[40]}$ and 0.048 for 2 (See Section 8 of SI for further details). However, when compared to room temperature data (1: 0.02 (in THF) ${ }^{[40]}$ and 2: $\left.0.015^{[28]}\right)$, the obtained superior values verified the absence of solid media. Secondly, deoxygenation of the enantioenriched solutions limited the photodegradation of the radical compounds once in the excited state. Hence, up to 100 scans, recorded in a broad fluorescence spectral range $(550-650 \mathrm{~nm}$ for 1 and $580-$ $680 \mathrm{~nm}$ for 2), were averaged in order to obtain clear CPL signals. Figure 3 (bottom) depicts the CPL spectra of the four enantiomers. As expected from a pure CPL response, opposite signed CPL activity was obtained for each pair of enantiomers and similar features to their respective total fluorescence spectra can be discerned. Remarkably, a perfect match with the signs of their 
respective Cotton effects for the ECD D bands was found. In this sense, the previously made $A C$ assignment was corroborated experimentally too. This good agreement can also be taken as a direct prove of the intrinsic CPL response of both atropisomers of 1 and $\mathbf{2}$. On the contrary, when analyzing the CPL activity of some achiral racemic mixtures included in chiral matrixes, some inconsistencies can be found. ${ }^{[59]}$ Regarding the different intensities detected in this work for the CPL spectra, they may arise from the large error in measurement due to the small values of the CPL. ${ }^{[18]} \mathrm{CPL}$ activity from the racemic mixtures of both compound was also evaluated at the same working conditions that in the case of the enantioenriched solutions $\left(10^{-4} \mathrm{M}\right.$ in $\mathrm{CCl}_{4}$, at $-20^{\circ} \mathrm{C}$ ), with a clear $\Delta \mathrm{l} \approx 0$ in both cases (see Fig. S16). In this sense, any significant contribution of linear polarization or optical artifacts was successfully ruled out. |glum $\mid$ of the CPL emission were also estimated as $\left(\times 10^{-3}\right): \approx 0.5$ for 1 and $\approx 0.8$ for 2 (See Fig. $\mathrm{S} 17-18$ in $\mathrm{SI}$ ). Despite moderate, no higher values were expected taking into account the $\left|g_{a b s}\right|$ values from $D$ bands (at 545 and $552 \mathrm{~nm}$ for 1 and 2, respectively). A relationship between dissymmetry factors $\left(\left|\mathrm{g}_{\mathrm{abs}}\right| /\left|\mathrm{g}_{\mathrm{lum}}\right|\right)$ was estimated as: 1.1 for 1 (x $\left.10^{-3}: 0.55 / 0.5\right)$ and 1.19 for 2 (x 10-3: 0.95/ 0.8). Since $\left|g_{a b s}\right| /\left|g_{\text {lum }}\right|$ were close to 1 , the dissymmetry was ensured at the excited state. ${ }^{[50]}$ This is also in agreement with the low Stokes shift values obtained from measurements in a viscous media at low temperature, where non-radiative deactivation pathways of the excited state are minimized. Comparing the results of $\mathbf{2}$ with respect to 1, the absorption and the emission of both compounds show that increasing the steric hindrance of the chiral structure leads to a more efficient chiroptical response. Consequently, as a first approach, new synthetic strategies that imply higher racemization barriers should be explored in further studies, in order to verify this hypothesis.

\section{Conclusion}

About seven decades after the first measurement of CPL activity ${ }^{[60]}$ this work presents the first results about the intrinsic chiral emission from enantiomeric organic free radicals. Two simple molecular propeller-like structures such as the stable tritylbased chlorinated radical derivatives, have been chosen for the given purpose. Besides their magnetic and electronic behavior, their conventional luminescence has been extensively reported, making chirality as their single most characteristic feature not properly explored yet. We strongly believe that, although moderate, the |glum| values here reported can be considered as a starting point for the development of improved chiral organic radical emitters. Taking full advantage of the numerously synthetic options these structures offers, several strategies can be followed from this moment on, in order to reach better CPL responses. Importantly, we expect the fundamental study here developed to lay the foundations for a new trend in optoelectronics and spintronics, where chiral, magnetic and luminescent properties can be used interchangeably in a single device. Thus, taking full advantage of the versatile nature of organic samples will place us a step further in the miniaturization race.

\section{Experimental Section}

Synthesis and chiral resolution. Radicals 1 and 2 were synthesized according to a previously published procedure for chlorinated trityl-based derivatives. ${ }^{[26]}$ Racemic resolution was carried out on an Agilent 1260 series equipped with the following modules: quaternary pump (G7111B 1260 Quat Pump), automatic sample injector (G2258A 1260 DL ALS), column thermostat (G1316A 1260 TCC), DAD detector (G7115A 1260 DADWR) and an automatic sample collector (G1364C 1260 FC-AS). CHIRALPAK® IC packed with cellulose tris-(3,5dichlorophenylcarbamate) immobilized on silica gel $(5 \mu \mathrm{m})$ was used as analytical column. The column temperature was set at $20^{\circ} \mathrm{C}$ and the flow was constant during operation $(1 \mathrm{~mL} / \mathrm{min})$.

Chiroptical spectroscopies. ECD and CPL measurements were carried out with an Olis DSM172 spectrophotometer, equipped with a $150 \mathrm{~W}$ xenon lamp. The spectra were recorded in two different concentration orders $\left(\sim 10^{-4}\right.$ and $\left.\sim 10^{-5} \mathrm{M}\right)$ in $\mathrm{CCl}_{4}$ at $-20^{\circ} \mathrm{C}$. For ECD measurements, a fixed slit width of $1 \mathrm{~mm}$ and an integration time of $0.5 \mathrm{~s}$ were used. For CPL measurements, fixed slits of 3 and $3.16 \mathrm{~mm}$, an excitation wavelength in the range of 370 and $385 \mathrm{~nm}$ with a $150 \mathrm{~W}$ xenon lamp and an integration time of $0.5 \mathrm{~s}$ were selected. The final CPL spectra were acquired with a 1 point/nm resolution and averaged from 100 scans. Significant contributions of linear polarization or optical artifacts were ruled out, and circular polarization was confirmed by observing the signal at a frequency of $2 \times 50 \mathrm{kHz}, 50 \mathrm{kHz}$ being the frequency of the piezoelastic modulator (PEM) acting as an oscillating quarter-wave plate in our equipment. ${ }^{[57]}$

Time-Dependent Density-Functional Theory (TD-DFT) calculations The ECD spectra of $\mathbf{1}$ and $\mathbf{2}$ were calculated at the minimum energy geometry computed at the DFT UB3LYP/6-311+G** level of theory implemented in the Gaussian 09 program package. [61] Harmonic frequencies were computed to verify that the found stationary points were true minima. TD-DFT was employed to describe electronic transitions at the same level of theory. A correction of $-0.3 \mathrm{eV}$ for $\mathbf{1}$ and $-0.2 \mathrm{eV}$ for $\mathbf{2}$ was applied to the calculated ECD spectra and a bandwidth of 0.3 and $0.25 \mathrm{eV}$ was applied for $\mathbf{1}$ and $\mathbf{2}$, respectively.

\section{Acknowledgements}

The authors are grateful for the financial support received from: MOTHER (MAT2016-80826-R) granted by the DGI (Spain), GenCat (2017-SGR-918) financed by DGR (Catalunya) and the Spanish Ministry of Economy and Competitiveness, through the "Severo Ochoa" Programme for Centres of Excellence in R\&D (SEV-2015-0496) and through the "Proyecto interdisciplinar de frontera“, FIP-2018 HECTIC-PTM. We acknowledge the European Research Council (ERC) under the European Union's Horizon 2020 research and innovation program (ERC-2015-STG677023). This study has been also supported by the Networking Research Center on Bioengineering, Biomaterials and Nanomedicine (CIBER-BBN), an initiative funded by the $\mathrm{VI}$ National R\&D\&I Plan 2008-2011, Iniciativa Ingenio 2010, Consolider Program, CIBER Actions and financed by the Instituto de Salud Carlos III with assistance from the European Regional Development Fund. P. M. B. gratefully acknowledges financial support from the Juan de la Cierva-Formación 2015 programme (FJCl-2015-23577) supported by MINECO. A. G. C. also thanks 
RyC-2013-12943 contract from MINECO. We also acknowledge Prof. O. Trapp for kindly suppling the DCxplorer software.

Keywords: organic radicals $\cdot$ chirality $\cdot$ chiroptical spectroscopies $\cdot$ absolute configuration $\cdot$ circularly polarized luminescence •

[1] Sánchez-Carnerero, E. M.; Agarrabeitia, A. R.; Moreno, F.; Maroto, B L.; Muller, G.; Ortiz, M. J.; de la Moya, S. Chem. Eur. J. 2015, 21 (39) 13488-13500

[2] Riehl, J. P.; Richardson, F. S. Chem. Rev. 1986, 86 (1)

[3] Yang, Y.; Da Costa, R. C.; Fuchter, M. J.; Campbell, A. J. Nat. Photonics 2013, 7 (8), 634-638

[4] Zinna, F.; Pasini, M.; Galeotti, F.; Botta, C.; Di Bari, L.; Giovanella, U. Adv. Funct. Mater. 2017, 27 (1)

[5] Li, M.; Li, S. H.; Zhang, D.; Cai, M.; Duan, L.; Fung, M. K.; Chen, C. F. Angew. Chemie - Int. Ed. 2018, 57 (11), 2889-2893

[6] Resa, S.; Miguel, D.; Guisán-Ceinos, S.; Mazzeo, G.; ChoquesilloLazarte, D.; Abbate, S.; Crovetto, L.; Cárdenas, D. J.; Carreño, M. C.; Ribagorda, M.; et al. Chem. Eur. J. 2018, 24 (11), 2653-2662

[7] Browne, W. R.; Feringa, B. L. Mol. Switch. Second Ed. 2011, 1, 121 179

[8] Takaishi, K.; Yasui, M.; Ema, T. J. Am. Chem. Soc. 2018, 140 (16), 5334-5338

[9] Reiné, P.; Ortuño, A. M.; Resa, S.; Álvarez de Cienfuegos, L.; Blanco, V.; Ruedas-Rama, M. J.; Mazzeo, G.; Abbate, S.; Lucotti, A.; Tommasini, M.; et al. Chem. Commun. 2018, 54 (99), 13985-13988

[10] Reiné, P.; Justicia, J.; Morcillo, S. P.; Abbate, S.; Vaz, B.; Ribagorda, M.; Orte, Á.; Álvarez De Cienfuegos, L.; Longhi, G.; Campaña, A. G.; et al. J. Org. Chem. 2018, 83 (8), 4455-4463

[11] Lunkley, J. L.; Shirotani, D.; Yamanari, K.; Kaizaki, S.; Muller, G. J. Am. Chem. Soc. 2008, 130 (42), 13814-13815

[12] Sawada, Y.; Furumi, S.; Takai, A.; Takeuchi, M.; Noguchi, K.; Tanaka K. J. Am. Chem. Soc. 2012, 134 (9), 4080-4083

[13] Morisaki, Y.; Gon, M.; Sasamori, T.; Tokitoh, N.; Chujo, Y. J. Am. Chem. Soc. 2014, 136 (9), 3350-3353

[14] Sato, S.; Yoshii, A.; Takahashi, S.; Furumi, S.; Takeuchi, M.; Isobe, H. Proc. Natl. Acad. Sci. 2017, 114 (50), 13097-13101

[15] Cruz, C. M.; Castro-Fernández, S.; Maçôas, E.; Cuerva, J. M.; Campaña, A. G. Angew. Chemie Int. Ed. 2018, 57 (45), 14782-14786

[16] Otani, T.; Tsuyuki, A.; Iwachi, T.; Someya, S.; Tateno, K.; Kawai, H.; Saito, T.; Kanyiva, K. S.; Shibata, T. Angew. Chemie - Int. Ed. 2017, 56 (14), 3906-3910

[17] Delgado, I. H.; Pascal, S.; Wallabregue, A.; Duwald, R.; Besnard, C.; Guénée, L.; Nançoz, C.; Vauthey, E.; Tovar, R. C.; Lunkley, J. L.; et al. Chem. Sci. 2016, 7 (7), 4685-4693

[18] Abbate, S.; Longhi, G.; Lebon, F.; Castiglioni, E.; Superchi, S.; Pisani, L.; Fontana, F.; Torricelli, F.; Caronna, T.; Villani, C.; et al. J. Phys. Chem. C 2014, 118 (3), 1682-1695

[19] Zinna, F.; Bruhn, T.; Guido, C. A.; Ahrens, J.; Bröring, M.; Di Bari, L.; Pescitelli, G. Chem. Eur. J. 2016, 22 (45), 16089-16098

[20] Inoue, Y.; Sakamaki, D.; Tsutsui, Y.; Gon, M.; Chujo, Y.; Seki, S. J. Am. Chem. Soc. 2018, 140 (23), 7152-7158
[21] Toyoda, M.; Imai, Y.; Mori, T. J. Phys. Chem. Lett. 2017, 8 (1), 42-48

[22] Qiao, W. G.; Xiong, J. Bin; Yuan, Y. X.; Zhang, H. C.; Yang, D.; Liu, M.; Zheng, Y. S. J. Mater. Chem. C 2018, 6 (13), 3427-3434

[23] Ballester, M. Acc. Chem. Res. 1985, 18 (12), 380-387

[24] Mislow, K. Acc. Chem. Res. 1976, 9 (1), 26-33

[25] Ratera, I.; Veciana, J. Chem. Soc. Rev. 2012, 41 (1), 303-349

[26] Armet, O.; Veciana, J.; Rovira, C.; Riera, J.; Castaner, J.; Molins, E.; Rius, J.; Miravitlles, C.; Olivella, S.; Brichfeus, J. J. Phys. Chem. 1987, 91 (22), 5608-5616

[27] Ballester, M.; Riera-Figueras, J.; Castaner, J.; Badfa, C.; Monso, J. M. J. Am. Chem. Soc. 1971, 93 (9), 2215-2225

[28] Fox, M. A.; Gaillard, E.; Chen, C. chung. J. Am. Chem. Soc. 1987, 109 (23), 7088-7094

[29] Ruberu, S. R.; Fox, M. A. J. Phys. Chem. 1993, 97 (1), 143-149

[30] Neier, E.; Arias Ugarte, R.; Rady, N.; Venkatesan, S.; Hudnall, T. W.; Zakhidov, A. Org. Electron. 2017, 44, 126-131

[31] Peng, Q.; Obolda, A.; Zhang, M.; Li, F. Angew. Chemie Int. Ed. 2015 54 (24), 7091-7095

[32] Ai, X.; Evans, E. W.; Dong, S.; Gillett, A. J.; Guo, H.; Chen, Y.; Hele, T. J. H.; Friend, R. H.; Li, F. Nature 2018, 563 (7732), 536-540

[33] Hattori, Y.; Kusamoto, T.; Nishihara, H. Angew. Chemie - Int. Ed. 2014, $53(44), 11845-11848$

[34] Hattori, Y.; Kusamoto, T.; Nishihara, H. Angew. Chemie - Int. Ed. 2015 , 54 (12), 3731-3734

[35] Hattori, Y.; Kusamoto, T.; Sato, T.; Nishihara, H. Chem. Commun. 2016, 52 (91), 13393-13396

[36] Kusamoto, T.; Kimura, S.; Ogino, Y.; Ohde, C.; Nishihara, H. Chem Eur. J. 2016, 22 (49), 17725-17733

[37] Kimura, S.; Tanushi, A.; Kusamoto, T.; Kochi, S.; Sato, T.; Nishihara, H. Chem. Sci. 2018, 9 (7), 1996-2007

[38] Castellanos, S.; Velasco, D.; López-Calahorra, F.; Brillas, E.; Julia, L. J. Org. Chem. 2008, 73 (10), 3759-3767

[39] Gao, Y.; Xu, W.; Ma, H.; Obolda, A.; Yan, W.; Dong, S.; Zhang, M.; Li, F. Chem. Mater. 2017, 29 (16), 6733-6739

[40] Blasi, D.; Nikolaidou, D. M.; Terenziani, F.; Ratera, I.; Veciana, J. Phys. Chem. Chem. Phys. 2017, 19 (13), 9313-9319

[41] Kimura, S.; Kusamoto, T.; Kimura, S.; Kato, K.; Teki, Y.; Nishihara, H. Angew. Chemie - Int. Ed. 2018, 57 (39), 12711-12715

[42] Veciana, J.; Crespo, M. I. Angew. Chemie Int. Ed. English 1991, 30 (1) 74-76

[43] Veciana, J.; Rovira, C.; Ventosa, N.; Crespo, M. I.; Palacio, F. J. Am. Chem. Soc. 1993, 115 (1), 57-64

[44] Irurre, J.; Santamaría, J.; González-rego, M. C. Chirality 1995, 7 (3), 154-157

[45] Trapp, O. Anal. Chem. 2006, 78 (1), 189-198

[46] Hayes, K. S.; Nagumo, M.; Blount, J. F.; Mislow, K. J. Am. Chem. Soc. 1980, 102 (8), 2773-2776

[47] Benincori, T.; Bonometti, V.; Cirilli, R.; Mussini, P. R.; Marchesi, A.; Pierini, M.; Pilati, T.; Rizzo, S.; Sannicolò, F. Chem. Eur. J. 2013, 19 (1), 165-181

[48] Driesschaert, B.; Robiette, R.; Lucaccioni, F.; Gallez, B.; MarchandBrynaert, J. Chem. Commun. 2011, 47 (16), 4793

[49] Tormyshev, V. M.; Genaev, A. M.; Sal'nikov, G. E.; Rogozhnikova, O. Y.; Troitskaya, T. I.; Trukhin, D. V.; Mamatyuk, V. I.; Fadeev, D. S.; Halpern, H. J. European J. Org. Chem. 2012, 2012 (3), 623-629 
[50] Tanaka, H.; Inoue, Y.; Mori, T. ChemPhotoChem 2018, 2 (5), 386-402

[51] Crabbé, P. ORD and CD in Chemistry and Biochemistry; Elsevier, 1972

[52] Warnke, I.; Furche, F. Wiley Interdiscip. Rev. Comput. Mol. Sci. 2012, 2 (1), 150-166

[53] Becke, A. D. J. Chem. Phys. 1993, 98 (7), 5648-5652

[54] Diez-Cabanes, V.; Seber, G.; Franco, C.; Bejarano, F.; Crivillers, N.; Mas-Torrent, M.; Veciana, J.; Rovira, C.; Cornil, J. ChemPhysChem 2018, 19 (19), 2572-2578

[55] Furche, F.; Ahlrichs, R.; Wachsmann, C.; Weber, E.; Sobanski, A.; Vögtle, F.; Grimme, S. J. Am. Chem. Soc. 2000, 122 (8), 1717-1724

[56] Cruz, C. M.; Márquez, I. R.; Mariz, I. F. A.; Blanco, V.; SánchezSánchez, C.; Sobrado, J. M.; Martín-Gago, J. A.; Cuerva, J. M.; Maçôas, E.; Campaña, A. G. Chem. Sci. 2018, 9 (16), 3917-3924

[57] Dekkers, H. P. J. M.; Moraal, P. F.; Timper, J. M.; Riehl, J. P. Appl. Spectrosc. 1985, 39 (5), 818-821

[58] Longhi, G.; Castiglioni, E.; Koshoubu, J.; Mazzeo, G.; Abbate, S. Chirality 2016, 28 (10), 696-707

[59] Jin, Q.; Chen, S.; Sang, Y.; Guo, H.; Dong, S.; Han, J.; Chen, W.; Yang, X.; Li, F.; Duan, P. Chem. Commun. 2019, 55 (46), 6583-6586

[60] Samoilov, B. J Exp Theor Phys 1948, 18, 1030-1040

[61] Frisch, M.; Trucks, G.; Schlegel, H.; Scuseria, G. Gaussian, Inc., Wallingford, CT. 2009 
Entry for the Table of Contents (Please choose one layout)

Layout 1:

\section{RESEARCH ARTICLE}

Highly efficient intrinsic chiral emission from enantiomeric organic free radicals has been explored, considering propeller-like trityl-based radical derivatives for such a purpose.

Layout 2:

\section{RESEARCH ARTICLE}

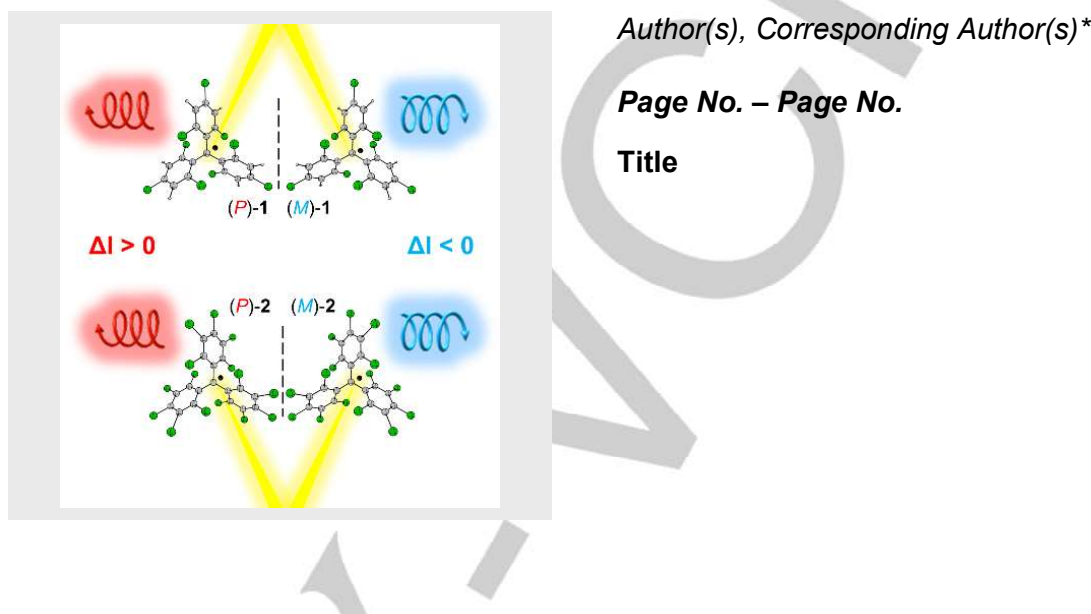

Author(s), Corresponding Author(s)*

Page No. - Page No.

Title

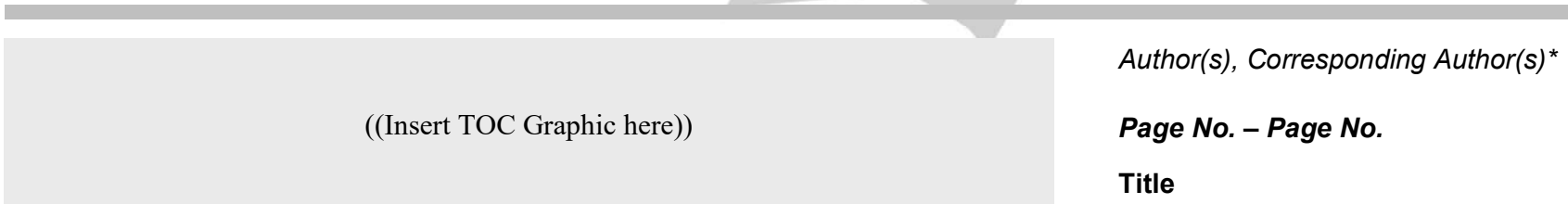

Text for Table of Contents 